\section{OPTIMUM PRECISION \\ FRAMEWORK}

The I-Bridge from BioHorizons, a screw-retained implant bridge milled from a single piece of titanium metal or fabricated in cobalt chrome, was recently launched in the UK through an exclusive arrangement with Biomain Sweden.

On receiving the impression from the dentist, the dental technician produces a model, designs the framework and sends it to Biomain in Sweden (via a courier pick-up service), where it is scanned digitally and converted to a data file. A high-end CAD/CAM milling machine produces the I-Bridge based on

\section{OUTSTANDING BESPOKE DESIGNS}

Whether updating current facilities or investing in a complete laboratory refurbishment, technicians can call upon Tavom's understanding and experience to create outstanding bespoke designs.

As one of the leading global manufacturers of cabinetry to the dental profession, Tavom offers more than 30 years of specialised knowledge and expertise. Worldwide, countless technicians benefit from their prompt and highly professional service on a daily basis.

Using the latest in CAD technology, skilled craftsmen and designers transform ideas into practical results, and Tavom's expert consultants are always available to offer solutions to all your laboratory cabinetry requirements.

\section{SMOOTH CEMENT}

Panadent has launched Seal Temp and Seal Temp S to the UK market: temporary crown and bridge luting cements with a smooth difference.

Seal Temp and Seal Temp S are suitable for any type of temporary crown on natural teeth. They are also the perfect choice for a prosthesis on an implant. Seal Temp is a more definitive cement, while Seal Temp S could be considered a semi-definitive cement because the crown can be removed, this scanned file, reproducing the bridge framework with optimum precision.

A perfect fit without any tension in the framework, I-Bridge is compatible with most major implant systems and available in three variations: I-Bridge, I-Bridge 2 and I-Bridge evolution, the choice depending on the case.

Reader response number 62

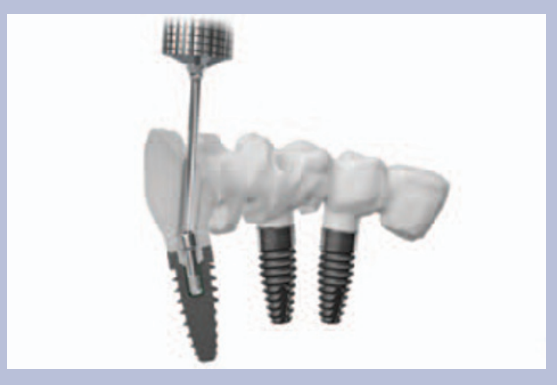

The EVO Lab System comprises durable surfaces, contemporary ergonomic design and innovative storage solutions. These improve both comfort and ease of operation while maximising the space available in the laboratory.

The extensive range allows the technician flexibility in creating the ideal laboratory setup. From design through to installation, Tavom can provide the solution to your requirements, exceeding all expectations.

Expertly combining functionality and aesthetic design, Tavom's Evo Lab cabinetry makes a noticeable difference in the efficiency and operational capabilities of any dental laboratory.

Reader response number 63

\section{STUNNING INTERIORS}

By shopping with Admor, you have the choice of thousands of cost effective, quality products to brighten up your surgery interior, and tell your patients that yours is a professional and efficient business.

When a patient walks into your surgery, the first thing they notice is not the quality of care that you provide, but your reception. As such it is vitally important that your reception area reflects your company ethos, and makes a good impression on your clients.

From large items to small, Admor can provide you with all your office needs. Whether it's a new reception desk and seating to remodel your waiting area, or art to hang on the wall of your treatment room, you can add style and elegance to your practice with items from Admor's 'Dental interiors' section.

When patients recommend their dentist to friends, their opinions are based on every aspect of the service they receive, so to help you create a business that offers the 'whole package', talk to Admor: the office essentials company for the dental industry.

\section{Reader response number 64}

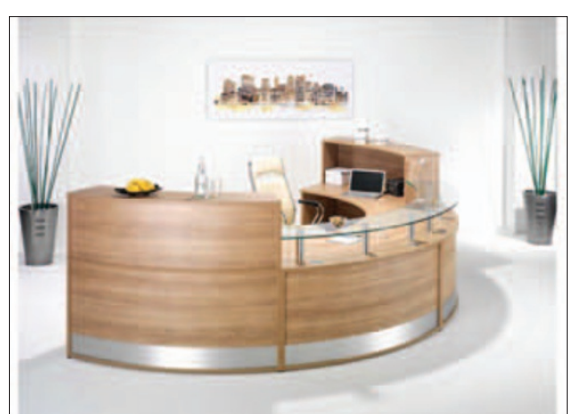

if necessary. Both cements give a very smooth gingival edge to the crown, ensuring fast and complete gum healing.

Panadent is also launching Elsodent's Duroc, a multi-purpose material made from a special combination of bi-acrylic resin, to achieve optimum strength. Its very low linear retraction is perfect for splinting implant transfers before impressions and its high flexural strength make it ideal for accurate and resistant bite registrations.
Duroc eliminates the risks of compression and deviation for accurate bite registration. Its thixotropic characteristics prevent Duroc from flowing into proximal areas.

Its thixotropy and its high strength are ideal to hold in place the two cutting parts of a bridge infrastructure when it needs to be repositioned. Duroc also burns without leaving a residue when it is crafted. Due to its extreme hardness, Duroc should not be used for undercuts.

Reader response number 65 